\title{
History of optics: a modern teaching tool
}

D. Vazquez, A. Gonzalez-Cano, N. Diaz-Herrera, N. Llombart, J. Alda

D. Vazquez, A. Gonzalez-Cano, N. Diaz-Herrera, N. Llombart, J. Alda, "History of optics: a modern teaching tool," Proc. SPIE 8481, Optics Education and Outreach II, $84810 \mathrm{U}$ (15 October 2012); doi: 10.1117/12.932271

Event: SPIE Optical Engineering + Applications, 2012, San Diego, California, United States 


\title{
History of Optics: a Modern Teaching Tool
}

\author{
D. Vázquez, A. González-Cano, N. Díaz-Herrera, N. Llombart, J. Alda \\ Departamento de Óptica, Universidad Complutense de Madrid, Escuela Universitaria de Óptica, \\ C/Arcos de Jalón, 118. 28037 Madrid. Spain. \\ dvazquez@opt.ucm.es
}

\begin{abstract}
The history of optics is a very rich field of science. It is possible to find many simple and significant examples of the application and success of the experimental method. Therefore, history of optics is a very good tool to teach students about the way science proceeds and to introduce the right spirit of critical analysis, building and testing of models, etc. Optical phenomena are specially well suited for this because, in fact, optical observations and visual experiments have made science advance in a significant way along different periods of history. In many cases experiments are essentially visual, and quite simple in concept. Besides they are easy to reproduce their experimental setups in classrooms. Also, the intrinsic multidisciplinary character of Optics, which is a subject that has historically influenced in a notorious way fields as art, philosophy, religion and cultural and social studies in general, provides a wide frame that permits to apply these examples to a large variety of learning levels. We present here some ideas about the role that history of optics can play in teaching and show some real examples of its application during the many years that we have been employing it in the context of the Optics School of the University Complutense of Madrid, Spain.
\end{abstract}

Keywords: History of Optics, Optics Teaching.

\section{INTRODUCTION}

The presence of Optics in the different curricula of scientific studies is somewhat unequal. Geometrical optics at the undergraduate level is typically scheduled during a few weeks in most of syllabi in physics and engineering majors. Some programs in optometry develop this topic long enough to analyze the propagation of light along the lens-eye system. In too many cases the background that secondary education should provide in Optics is not as good as it is should be, and to make the students become acquainted with the main theories and results in Optics is a difficult work.

But, at the same time, many of the subjects of elementary Optics are in fact quite familiar to the students, being related, as they are, to everyday activities or objects (sight and its limitations, lamps and illumination, instruments such as mirrors, lenses, etc.). This does not always favor the labor of the teacher if he/she is not prepared to somewhat "re-program" this knowledge to make compatible a sound scientific formation with the sometimes erroneous thinking of the students. These prejudices, obtained by a priori, commonly involuntary applications of rudimentary experiments and essay-anderror procedures, need to be corrected before constructing a viable non-academic Optics that anyone always need because of the unparamount importance of optical phenomena in our common lives.

So we find that, on one hand, we must introduce in a fast, efficient way the most important concepts of Optics to different types of students with different interests and requirements and, on the other hand, that we must take into account (and, most importantly, that we can take advantage of) this familiarity. In a certain way, we must proceed to a construction of academic Optics (much in the same way that we must construct many other subjects during the years of undergraduate studies) and what we propose here, based in many years of successful experiences, is to use the history of Optics as a major, powerful tool in that construction.

The intrinsic experimental simplicity of many crucial developments of Optics, and the highly important role that Optics has played in fact in the development of modern Science, also helps to increase the general knowledge of the students about the ways science progresses. The position of a student when trying to know how a phenomenon can be explained is not that different to the position adopted by scientists and pre-scientists when studying that phenomenon for the first time. Besides, as we have said before, every student has been in front of many optical everyday phenomena since he/she 
was a child. A diachronic study of the evolution of Optics is then highly indicated from the pedagogic point of view. Also, as the implications of optical discoveries and theories in many fields (such as art, philosophy, religion, and social and cultural studies in general) are so many, there exists a lot of different approaches and suggestions to be made to the students to extend the study by themselves and to find examples of the influence of Optics in their world, in the way they live in it and the way they see it.

The material presented here has been developed during the many years we have been teaching history of Optics as an elective subject in the under-graduated studies of the degree of Optics and Optometry. Therefore it has been tested many times, with different students, many of them in their first semesters, and with very little previous scientific knowledge of Optics. During this time we have observed how this approach encourages participation, and the degree of compromise of our students of history of Optics can be considered above average. In the teaching of other subjects in Optics in the degrees of Optics and Optometry and Physics we have also taken profit of the historical approach to the matters, and, again, with good results.

To summarize, the main advantages of using the historical approach in the teaching of Optics in our opinion are:

1.- Students can easily mimic the circumstances and elements used by the scientist at the time: "If they solved these problems with very simple tools and media we can do the same". This is highly motivating and results in very dynamic and entertaining sessions.

2.- Scientific method is the way to build valid knowledge, and this is easily shown during the time of the lecture, and can be discussed before and after the experiment, showing in this way the particularities of the scientific method when compared with other possibilities of addressing the problems.

3.- The experimental capabilities of the students are increased, specifically the analysis of the sources of uncertainties, the need to isolate the effects from unwanted influences from the environment, and the compulsion to optimize the setup and minimize its complexity as far as it is possible.

4.- The critical approach that is necessarily adopted, not only in the realization of the experiments but in the definition of the conditions, the building of the setup and the ultimate result analysis, permits to the student to develop his/her capabilities for abstract reasoning, and philosophical argumentation. Many times the practical lectures are based on highly developed setups, with not very adaptable and quite closed experiments that tend to impose on the students a passive attitude. This is completely different with the historical experiments we use.

5.- Optics has played a very important role in the development of science in general and it is very easy to find historical experiments of high transcendence. This fact can help to understand the very mechanism of progress in science. Also, since the field of optics includes the study of very well-known of important features, such as light or vision, it is by nature a multidisciplinary subject, where the purely scientific approach commonly coexists with many other implications in other field, such as art, philosophy, religion, and culture in general.

In the subsequent sections we show some examples of the many experiments made by us along these years, without being exhaustive or too detailed. The main goal of this work is not necessarily to recommend these particular options, but to show, in a general way, a certain philosophy of teaching and to encourage to every teacher to develop his/her particular setups and practical approaches.

\section{REFLECTION LAW}

For ages, mirrors have been considered as mysterious and tricky objects. They confront the image of the observed and produce a self-awareness that is impossible without them. From very ancient times, humankind has used quiet water, and polished surface for this task, and metallic mirrors have been found in many excavation sites, the oldest ones having an age of several thousand years [1,2]. Everyone has mirrors at home, and everyone has developed small, perhaps not-tooconscientious experiments to become acquainted to them. The everlasting fascination of mirrors is a very favorable starting point for the application of our method of teaching. In fact, it is curious to observe how students (and people in general) keep misconceptions about mirrors and how fruitful is the mere discussion of very simple questions. But the most amazing part of these discussions is that in many cases these misconceptions relate directly to ancient theories adopted, for instance, in the frame of Greek Alexandrian mathematical Optics [3,4]. A simple example: many of the questioned students consider that if one is looking his/herself in a mirror and it suddenly becomes completely dark in the room, 
his/her image is still on the mirror, waiting for him/her to see it, and the only impossibility of such contemplation if of the same kind of that related in general to a lack of a source of illumination, that is to say: "we cannot see a table in the dark, but it is there; it is the same thing with our image". This implies that the students opt for a material, tactile condition of the image, that is produced by the mirror as a consequence of our mere presence, but has nothing in fact to do with the (secondary) emission of light of our body. This is easily related to ancient theories of imaging and sight and we can take advantage of the study of Greek catoptrics to show how the understanding of optical reflection was improved along the ages and how the scientific conception of mirroring was changing at a very different pace (as we see) of common, everyday, every-person knowledge. And this is but one of the many examples of this, so to speak, philosophical experiments.

Another different example that we can provide is the realization of a very simple experiment that can permit us to check reflection law. This experiment has always provided a lot of fun to the students. Simple as it may be (and one must take into account that our method precludes sophisticated setups and encourages students to design the experiment with the available media) it induces a profound reflection as:

\section{1: How one must understand vision and}

2. How one can measure anything and the limitations inherent to that measurement process.

The experiment is depicted in Euclid's Optics (proposition XIX) and presupposes the knowledge of reflection law [5]. In fact, as perhaps reflection law was known by the Platonic school and some has pointed to Philip of Opus as his discoverer, the first evidence of that knowledge comes from that work of Euclid, which has been transmitted in a somewhat complicated, but essentially literal way. There exists many other sources of Greek catoptrics, that are analyzed by us with the students, and one of those is, of course, the Catoptrics traditionally attributed to Euclid, but most probably authored by Theon of Alexandria many centuries afterwards. In that pseudo-euclidean Catoptrics, reflection law is enunciated as a postulate, but it is obvious that this law has already been established by the time of the redaction of the $O p$ tics. By the way, this kind of historical discussions are always well received by the students if kept in a colloquial level, not trying to be erudite, because they show to them the role that chance plays in the development of science and how important has been during the history of humanity, before the age of print the transmission of the manuscripts between different peoples and ages.

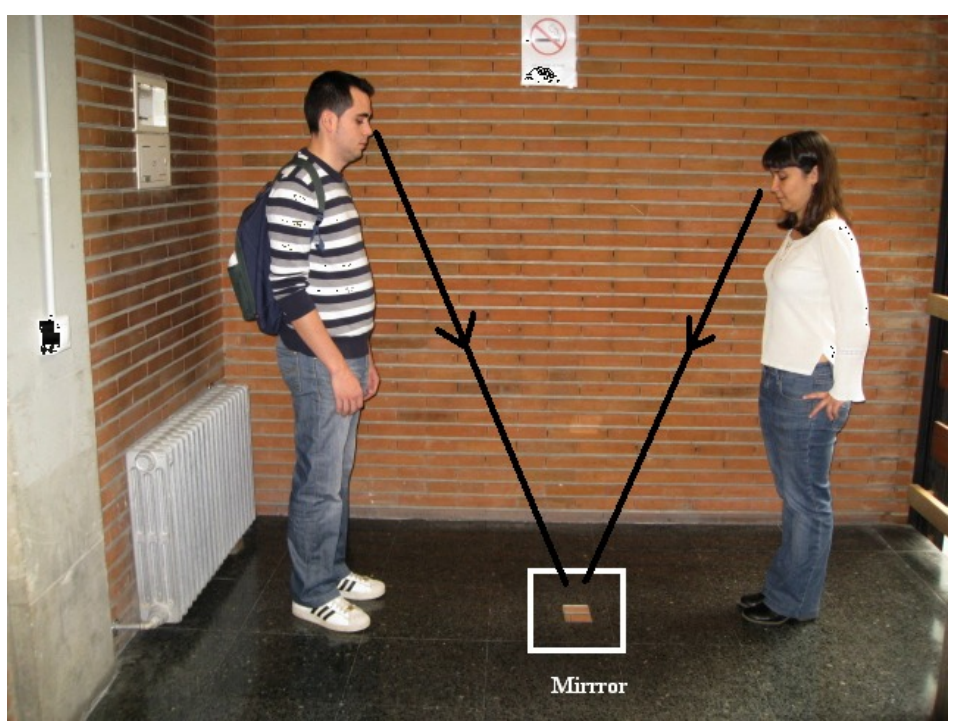

Figure 1. Checking reflection law

In the experiment, Euclid shows us "a way of measuring heights when it is not sunny" (because if it is sunny one can use shadows). The idea is simple, since reflection law establishes the equality of incidence and reflection angles (taken with respect to the surface if one does not want to fall into anachronism) one has two similar triangles and known three of the magnitudes in question (one height and two lateral distances), one can deduce the other one. Well, the only material the students will have them is one mirror and a metric tape. Of course, they all know reflection law because they have learned it before. However, they must take into account that Euclid, and all the other Alexandrian mathematical opticians, developed their laws in a extramissive context, assuming that sight proceeds in a rather tactile way from the eyes. In the beginning of this lab session it is not easy for the students to abandon their drawings and raytracings, not to be able to directly measure angles, and to have to think the best way of performing measurements to reduce uncertainties... But, after some minutes they find the way and they can, first, check reflection law by taking each other as observed object (the eye contact through a small mirror on the floor is easily recognizable and therefore uncertainties are reduced) and then to measure any height of any distant object they want. And then, of course, they must calculate the errors produced in the measurement process, and to discuss the ways in which it can be improved. 


\section{PRINCIPLE OF LEAST TIME}

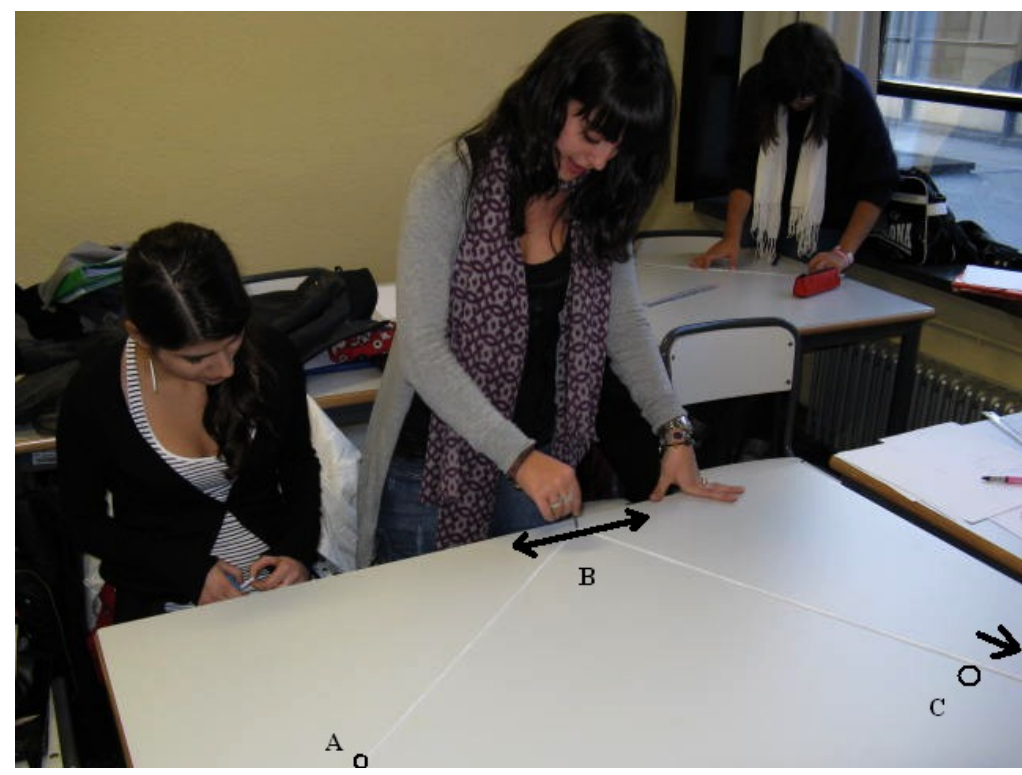

Figure 2. Testing the principle of least distance

Extreme principles are most important for the development and theoretical Physics, as it is easily shown in the field of dynamics. Also, its discussion is also very interesting from the point of view of the teleological, non-scientific influences on pre-conceptions and how they have been used along history. One very basic (the first one in time, in fact) version of the socalled principle of economy of nature, that lies behind any other extreme principle in Science is Hero's principle of least time applied to the path of light in reflection, as established in its work on Catoptrics [6]. We can easily check Hero's principle with a very simple arrangement, only with a cord and some pins. We fix two points, the beginning and the end of the trajectory, considered as fixed. The location of the reflecting surface is then considered and the cord has to touch the reflecting surface at a given point (the incidence point on the surface), in such a manner that the length of the cord has to be minimized. In this situation, the students realize that the incidence and reflected angles are equal. Usually, the error in the angular determination is large, because there are unwanted effects such as the elongation of the cords, and therefore, as simple as the setup is, again the discussion on sources of uncertainty must be carried carefully.

In the case of refraction, the proceeding is similar to the method explained for reflection. Now, we are testing the Fermat law for refraction, and we need to comprehend the optical patch concept, that is the product of the geometrical path times the index of refraction. To facilitate the math we assume that the index of refraction of the second media is equal to 2 . That means the optical path in second media is twice longer than in the first media. To properly model this situation we double the string when it represents the optical path in the medium having index equal to 2 . In this case the student must find out the light path from point 1 to point 2 . The student moves the point 3 along the line (interface surface) until the total length of the cord reaches a minimum.

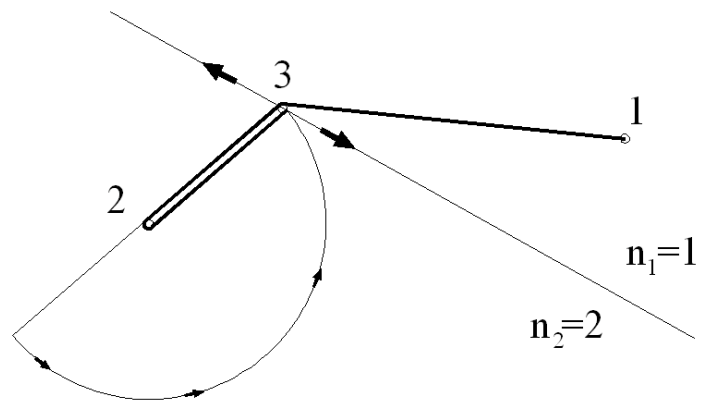

Fig.3.- Scheme of Fermat hypothesis test for refraction law 
For making the practice points 1 and 2 must be fix. The student have to tie up the string to point 1 and carry it until point 2 and then turn it until point 3 , the student have to move point 3 along the interface between medias. When they find the minimal distance of the string they must calculate the incident and refracted angles and verify the Snell law.

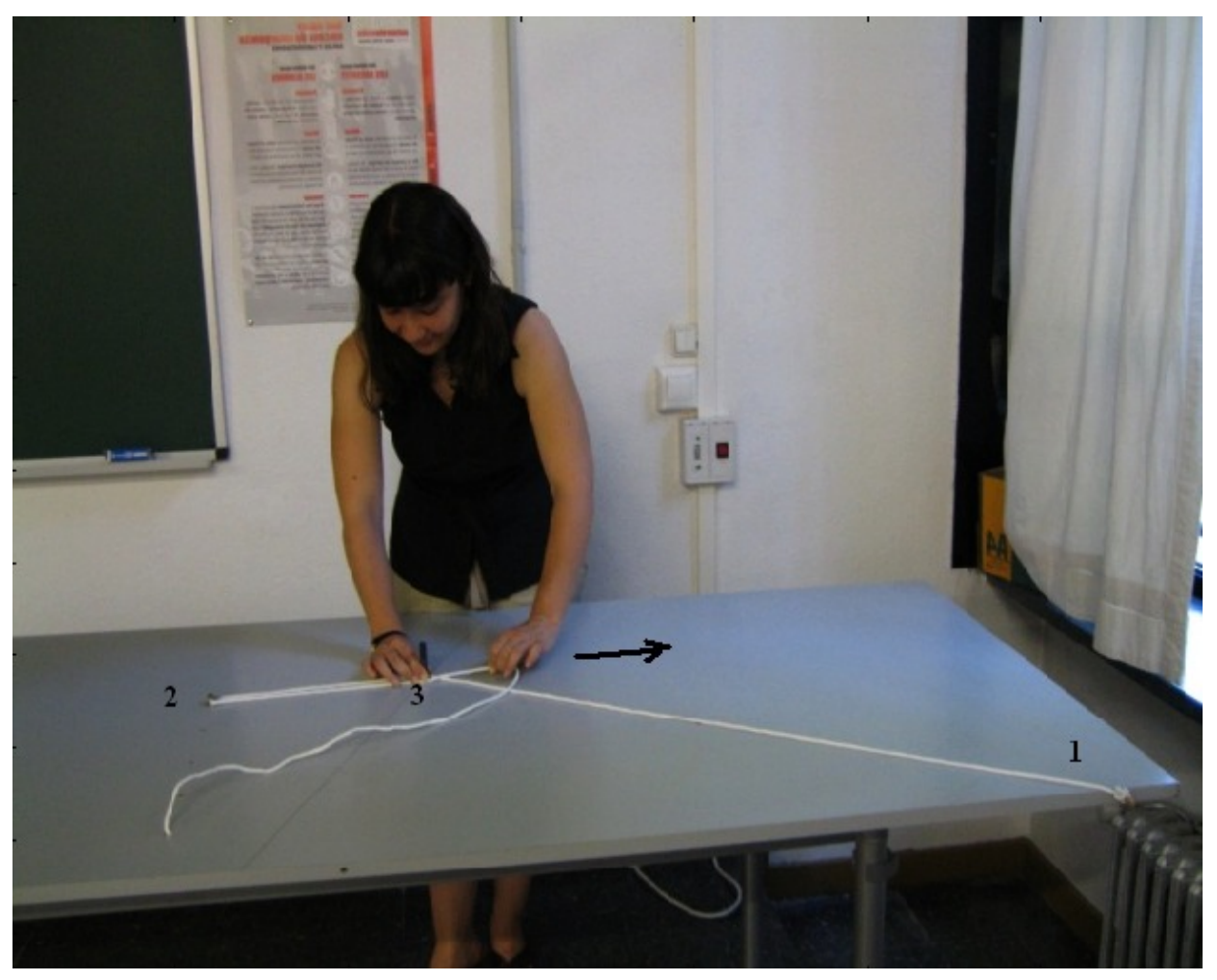

Fig.4.- Real Fermat hypothesis test for refraction law

It is easy to extend the discussion to other minimum principles, and in the context of the class one can also introduce the question of the hierarchy of scientific enunciates, the role of philosophical rules such as Ockham's razor, etc.

\section{THE WORK OF BENITO DAZA DE VALDÉS AND THE MEASURE OF THE OPTICAL POWER OF LENSES}

We could provide many other examples of application of our method to other optical laws and phenomena, but we would like to close this brief summary with some lines on one of the most prominent Spanish scientists in the field of Optics: Benito Daza de Valdés. The fact that he was a Spaniard is important, because it permits to establish his historical context in an easier way, with much more familiar references, and because, in this particular case, the period where Daza de Valdés lived was a most prominent era in Spanish history, especially in cultural terms (the so-called Golden Age) [7]. Of course, in other different countries or areas, we can do the same thing with other authors, but it is important to take into account that any additional historical information that we can provide to the students (or found by themselves) will be more interesting to them if they find it somewhat near to them.

But in this case Daza de Valdés's work was important enough to study it in our course of history of Optics. His procedure was the first experimental method of establishing the optical power of lenses, and in his work Uso de los antojos 
para todo genero de vistas ("The use of eyeglasses for any visual condition") [8] he proposes numerous experiments to assess the optical acuity of a subject and the best way to improve it. Although eyeglasses had already been used for centuries they remained in the early seventeenth centuries largely a matter of artisans and street salesmen. Della Porta, Maurolico and Kepler had provided a first-order geometrical optics able to explain the way ophthalmic lenses work and how they could be used to improve our visual acuity. But the reality is that such simple tasks as determining which was the required prescription for a non-present user were in fact impossible, because of the lack of a systematization of the knowledge in the field of visual optics and the non-existence of reliable measuring and characterizing methods for lenses.

We analyze in the classroom the work of Daza de Valdés from different point of views and we propose several experiments, strictly following the way in which he exposes them in his work. One of the most important is the way he depicts to establish the optical power of lenses (measured in grados, that is, degrees: nowadays, in Spain we commonly speak of graduación to refer to the refraction of a subject). Essentially, one must visually compare two circles (provided by Daza in the pages of his book), one of them seen directly and the other one seen through the problem lens. By moving this with respect to the test (keeping our point of view fixed) the magnification changes and at some point the two sizes of the circles will become apparently equal. We then determine the distance between lens and test object by using a rod perpendicular to the plane of the test, that we can take to a scale in the same page of the book where the different degrees are shown (figure 5). Daza provides different schemes for positive and negative lenses.

It is very interesting to see how students cope with the difficulties of interpreting an original source, and how amazingly accurate can be the test when carefully performed (although, of course, the practical limitations become obvious for some values of the power and the influence of some factors such as unwanted movement of the point of view is evident). We measure different common, commercial, non-expensive ophthalmic lenses and try to make a fitting of the results to a curve, in that way establishing the grado-diopter equivalence.

Daza also provides a way of relating the optical power of the lenses to their curvature and to measure in a simple way the visual acuity of the subjects (by discerning, at a distance, tiny objects, mustard seeds in this case). We also reproduce these experiments by following the same approach of directly dealing with the original tests.
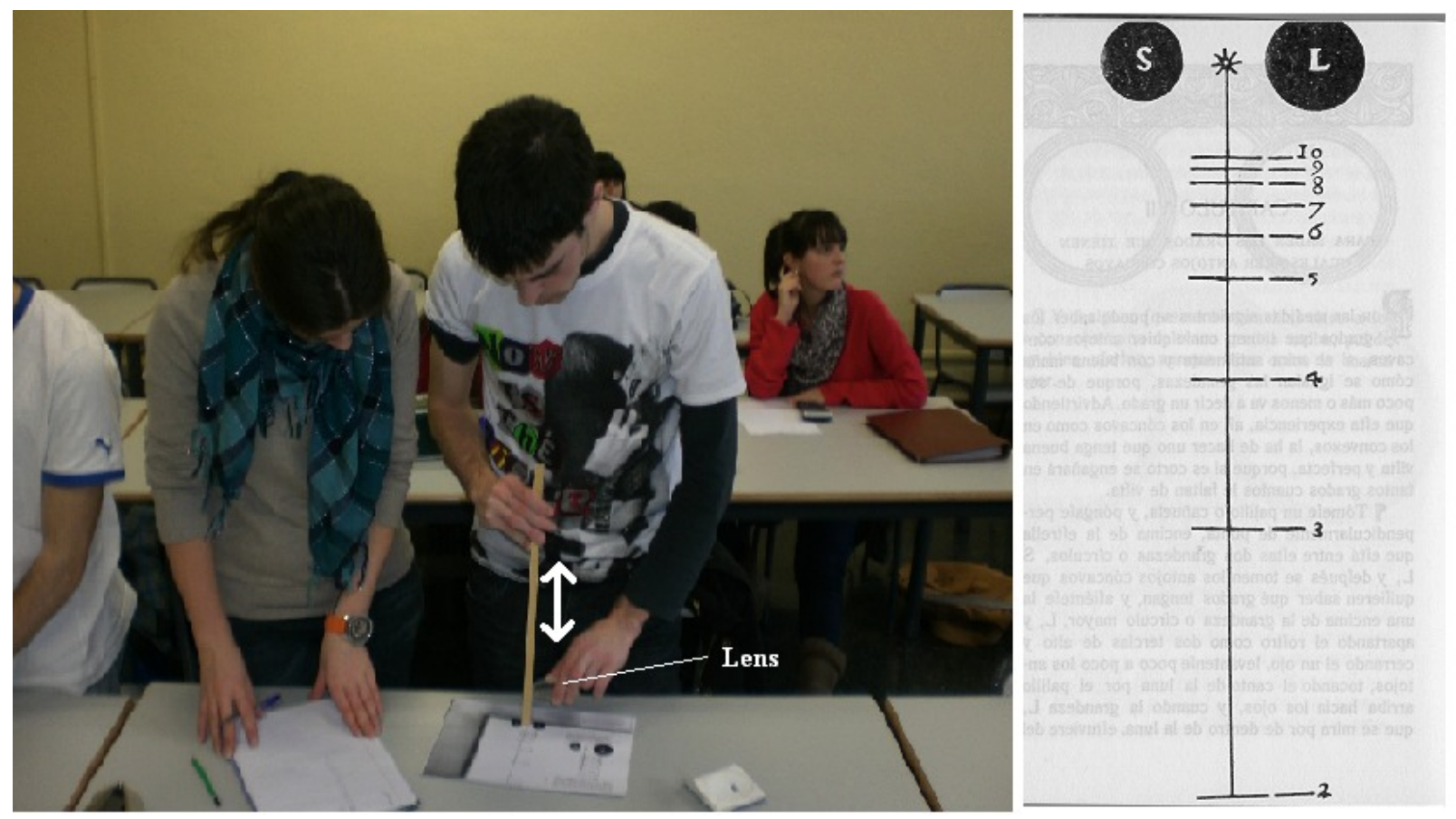

Fig.5.- Measurement of lens power by Daza de Valdés's method, and a reproduction of the original scale provided by Daza. 


\section{CONCLUSIONS}

Here we have presented only a brief outline of what can be considered a method for using history of Optics not only as an optimum, enjoyable way of introducing the basic facts and concepts of Optics, but also as a powerful tool to introduce the main facts of Physics, the difficulties and advantages of the scientific method and the connections between science and common-day life. The method has been tested for many years with very good results and the possibilities that Optics and optical phenomena have to improve in a general way the learning process are many.

\section{REFERENCES}

[1] J. Baltrusaitis, Le miroir: essai sur une legende scientifique, Elmayan, Paris, 1978.

[2] S. Melchior-Bonnet, Histoire du miroir, Eds. Imago, Paris, 1994.

[3] G. Simon, Le regard, l'être et l'apparence dans l'Optique de l'Antiquité, Seuil, Paris, 1988.

[4] McCarty, Willard (1989). "The Shape of the Mirror: Metaphorical Catoptrics in Classical Literature". Arethusa, 22, 161-95.

[5] Euclides, Óptica, Catóptrica, Fenómenos. Gredos, Madrid, 2000.

[6] Heath, Thomas (1981). A history of greek mathematics. Vol.1, From Thales to Euclid y vol.2, From Aristarchus to Diophantus. Dover Publications, Nueva York. [Original date of publication: 1921.]

[7] A. González-Cano, "Un poema del siglo de Oro español sobre los anteojos", Óptica pura y aplicada, 37, 33-43 (2004).

[8] Benito Daza de Valdés, Uso de los antojos para todo genero de vistas, Sevilla, 1613. 